\title{
Voces rurales y urbanas del Conflicto Armado, la Violencia y Paz en Colombia ${ }^{4}$
}

\author{
Bibiana Andrea Torres Orjuela \\ Estudiante de Psicología \\ Universidad Santo Tomás \\ Bogotá, Colombia \\ Correo: bibis.021@hotmail.com
}

Diego Leonardo Díaz Díaz

Estudiante de Psicología Universidad Santo Tomás Bogotá, Colombia

Correo: Diegoleonardod2@gmail.com

Yésica Alejandra Durán Parra

Estudiante de Psicología Universidad Santo Tomás Bogotá, Colombia

Correo: Yesicaduran@usantotomas.edu.co

Erika Paola Salamanca Beltrán Estudiante de Psicología Universidad Santo Tomás Bogotá, Colombia

Correo: erika-salamanca_b@hotmail.com

\author{
Estefanía Mera Quiñónez \\ Estudiante de Psicología \\ Universidad Santo Tomás \\ Bogotá, Colombia
}

Correo: estefaniamera@usantotomas.edu.co

\author{
Daniel Alejandro Socha Castelblanco \\ Estudiante de Psicología \\ Universidad Santo Tomás \\ Bogotá, Colombia \\ Correo: dalejandro0506@gmail.com
}

Vicky Xiomara Donoso García Estudiante de Psicología Universidad Santo Tomás Bogotá, Colombia

Correo: vicky.donoso@usantotomas.edu.co
Yakeline Stefania Lozano Beltrán
Estudiante de Psicología Universidad Santo Tomás Bogotá, Colombia
Correo: yakelinelozano@usantotomas.edu.co
María Liliana Lozano Piedrahita
Estudiante de Psicología
Universidad Santo Tomás Bogotá, Colombia
Correo: maria.lozanop@usantotomas.edu.co
Karen Viviana Guzmán Orjuela
Estudiante de Psicología Universidad Santo Tomás Bogotá, Colombia
Correo: karennguzman@usantotomas.edu.co

Recibido: 13/04/2015 Evaluado: $4 / 02 / 2016$ Aceptado: 28/02/2016

\section{Resumen}

Obejtivo: comprender los significados, que la población civil participante indirecta en el conflicto armado, residente en los territorios rural y urbano, ha construido en torno a los fenómenos de la violencia, la paz y el conflicto armado en Colombia. Método: desde un enfoque construccionista y un método hermenéutico, se realizó un análisis de contenido de la información recolectada en cinco grupos focales a la luz de tres grandes categorías (Influencia Histórico-Cultural, Sentidos y Eventos). Resultados: se destaca que los significados en torno a la paz y la violencia se construyen desde el contexto familiar y sistemas cercanos a éste como instituciones educativas, comunidad, entre otras. Conclusión: Ios participantes relacionan el conflicto armado con grupos al margen de la ley y su ideología polarizada respecto al Estado, identificando a la población civil como el actor mayormente afectado. Las acciones cotidianas se reafirman como posibilidades de construcción de paz.

Palabras clave

conflicto armado, violencia, paz y población civil indirectamente afectada por el conflicto.

4 Para Citar este artículo: Socha, D., Lozano, K., Lozano, M., Guzmán, K., Torres, B., Díaz, D, Duran, Y., Salamanca, P., \& Mera, S. (2016). Niveles de autoestima y uso de estrategias de afrontamiento en personas privadas de la libertad en un centro de reclusión de la ciudad de Bucaramanga. Informes Psicológicos, 16(1), pp. 65-84 http://dx.doi. org/10.18566/infpsicv16n1a04 


\section{Country and urban voices of the armed conflict, violence and peace in Colombia}

Abstract

Objective: To identify those strategies used by subjects in situations perceived as stressful, and to correlate self-esteem with coping strategies. Method: Study of the descriptive correlational kind that assessed selfesteem through the Coopersmith Self-Esteem Inventory, which supports reliability and validity coefficients between .81 and .93. Furthermore, the use of coping strategies was examined by the Coping Strategies Scale Modified, EEC-M, which manages a Cronbach's alpha of .847. These tests were administered to a group of 41 people arrested in the Medium Security Penitentiary and Prison of Bucaramanga for various offenses .. Results: it is evident that the total level of self-esteem is qualitatively placed as normal according to a cutoff of 15.78 in the general scale. However, in general, social and family-home test results subscales downward trend was evident. Furthermore, frequent use and high score on the coping strategies that refer to Troubleshooting, Religion and positive reappraisal, was observed Conclusion: there are significant correlations $(p<.05)$ of negative type between self-esteem and strategies of Waiting coping, Emotional Avoidance, Aggressive Reaction and Denial.

\section{Vozes rurais e urbanas do conflito armado, a violência e paz na Colômbia}

Resumo

Objetivo: Identificar aquelas estratégias utilizadas pelos sujeitos ante situações percebidas como estressantes, ademais se correlacionar a autoestima com as estratégias de afrontamento. Método: estudo de tipo descritivo-correlacional avaliou a autoestima através do Inventário de Autoestima de Coopersmith, 0 qual sustem coeficientes de confiabilidade e validez entre .81 e .93. Ademais, se examinou 0 uso de estratégias de afrontamento, mediante a Escala de Estratégias de Afrontamento Modificada, EEC-M, a qual maneja um alfa de Cronbach de .847. Estas provas foram administradas a um grupo de 41 pessoas detidas no Estabelecimento Penitenciário de Mediana Seguridade e Prisional de Bucaramanga por delitos diversos. Resultados: se evidencia que o nível total de autoestima se situa qualitativamente como normal segundo ponto de corte de 15,78 na escala geral, porém, nas sub-escalas geral, social e família-lar da prova se evidenciaram resultados com tendência à baixa. Por outra parte, se observou 0 uso frequente e alta pontuação nas estratégias de afrontamento que referem a Solução de Problemas, Religião e Re-avaliação Positiva, Conclusão: existem correlaciones significativas $(p<.05)$ de tipo negativo entre a autoestima e as estratégias de afrontamento de Espera, Prevenção Emocional, Reação Agressiva e Negação. 


\section{ntroducción}

Con la intención de generar un espacio de reflexión y crítica disciplinar e interdisciplinar frente a las necesidades el contexto Colombiano, estudiantes de diferentes semestres académicos de la Facultad de Psicología de la Universidad Santo Tomás (Bogotá, Colombia), el semillero "Jajebëam Paz, Visibilizando memorias, transformando silencios" desde hace tres años aproximadamente; este grupo se constituye como una apuesta de investigación y debate sobre la realidad sociopolítica colombiana, por tal razón, desarrolló la investigación "Voces rurales y urbanas del conflicto, armado, la violencia y la paz en Colombia", apoyada por la Universidad y por COLCIENCIAS (Departamento Administrativo de Ciencia, Tecnología e Innovación, entidad gubernamental de Colombia) en el marco de la convocatoria nacional para el programa de jóvenes investigadores e innovadores del 2013.

Teniendo en cuenta que los sistemas sociopolíticos afectan las dinámicas culturales locales y cotidianas (Botero, Pinilla, Lugo, \& Calle, 2012), donde las narraciones son las que permiten evidenciar las percepciones, posiciones y actitudes particulares de los habitantes de un territorio específico (Calle, 2011), la investigación "Voces rurales y urbanas del Conflicto Armado, la Violencia y Paz en Colombia", tuvo como finalidad comprender los significados que las poblacionespoblaciones civil rural y urbana, no afectadasafectadas directamente por el conflicto, hanhan construido en torno a los fenómenos de la violencia, la paz y el conflicto armado. Incluso para autores como Rettberg (2002), se hace necesario visibilizar las diferentes versiones de la historia y construir escenarios de diálogo que garanticen la no repetición y la construcción de paz duradera en Colombia.

La investigación parte desde la perspectiva del construccionismo social para reconocer que a partir de las negociaciones que se dan en las interacciones y dinámicas relacionales (entre los sujetos, lugares, momentos y objetos) surgen significados, que son susceptibles constantemente a la deconstrucción y co-construcción, generando nuevas posibilidades de cambio. Es el lenguaje, como vehículo de transformación de los significados, la herramienta que cohesiona a una sociedad y que permite mantener, construir y comprender sentidos comunes a los sujetos que hacen parte de éstaésta (Gergen, 1996, 2006, citado por Arcila, Mendoza, Jaramillo, \& Cañón, 2010). Por su parte, Bruner (1996, 2006, citado por Arcila, Mendoza, Jaramillo, \&Cañón, 2010) asume que dicha negociación de los significados está mediada por el contexto cultural en el que los sujetos están inmersos. El mismo autor añadeañade la definición de la negociación como la acción de consensuar los significados para participar en la cultura, asumiendo que la función de los significados es conectar al hombre con ésta y facilitar su transformación mutua.

La revisión de referentes teóricos respecto a las categorías las cuales son conflicto armado, violencia y paz como fenómenos sociales dinámicos e interdependientes, mostró algunos aspectos relevantes que se sintetizan a continuación: 


\section{Conflicto Armado}

El conflicto es un fenómeno inherente al ser humano y sus dinámicas relacionales, donde se presenta la incompatibilidad de creencias, valores o afectos entre dos o más partes (Parra, 2008). De la concepción que se tenga del conflicto dependerá su abordaje, siendo la violencia tan solo una de las posibilidades para su resolución. Los Convenios de Ginebra de 1949, que se han destinado a escenarios de conflicto entre un Estado y una organización armada o entre varias de ellas, definen en el Protocolo II adicional del 7777 los conflictos armados internos como aquellos que se "desarrollen en el territorio de una Alta Parte contratante entre sus fuerzas armadas y fuerzas armadas disidentes o grupos armados organizados que, bajo la dirección de un mando responsable, ejerzan sobre una parte de dicho territorio un control tal que les permita realizar operaciones militares sostenidas y concertadas" (Comité Internacional de la Cruz Roja, 1977, citado por Arévalo, 2014). Ahora bien, a partir de esta definición se puede reconocer que la situación de conflicto que se vive en Colombia puede ser vista como un conflicto armado interno.

Pese a esta claridad, el conflicto tiene diferentes definiciones de acuerdo a la perspectiva de los diferentes actores sociales que hacen parte de él; para las guerrillas, la guerra ha sido relacionada con la lucha por la transformación estructural de la sociedad y el empoderamiento de las poblaciones excluidas. La guerra ha sido reconocida por el Estado Colombiano como una lucha contra el terrorismo y la defensa de la democracia y los modelos económicos establecidos (Comisión Intereclesial de Justicia y Paz,
2013), teniendo presentes las implicaciones de declarar a los grupos armados ilegales como beligerantes y obviando que el estatus de conflicto armado interno no necesariamente está determinado por la condición política de los grupos armados ilegales (Arévalo, 14 de junio de 2014).

El Grupo de Memoria Histórica (2013) identifica que los factores que han influido en la prolongación del conflicto interno colombiano son: el problema agrario (ausencia de políticas públicas, concentración de la tierra y abandono de lo rural), la falsa instauración de la democracia (vista como oportunidad, ausencia y deslegitimación de la oposición), el narcotráfico (que ha proveído de recursos económicos a todos los actores armados del país); dinámicas de guerra internacionales (como la Guerra Fría, que en su momento generó rivalidades de índole sociopolítica en las dinámicas internas de varios países, entre esos Colombia ) y la fragmentación territorial e institucional del Estado.

De acuerdo con el Grupo de Memoria Histórica (2013) y Amnistía internacional (2008), el conflicto armado colombiano tendría como principal actor afectado a la población civil, en la medida en la que se ve involucrada como una fuente de respaldo político, económico, moral y logístico (consentido o forzado), para los grupos armados ilegales y legales (Grupo de Memoria histórica, 2013). Se habla de 6.996.539 víctimas registradas por el conflicto armado para febrero del presente año (Unidad para la atención y reparación integral a las víctimas, 2015). También se reconocen afectaciones a la salud mental, la cultura cotidiana y las dinámicas relacionales de los 
colombianos, afectados directa o indirectamente por este (Mogollón, Vásquez, \& García, 2003). A la luz de este tipo de fenómenos, la definición de conflicto armado también puede ser explorada desde la óptica de la psicología política, que lo asume como el proceso de resistencia comunitaria consolidado por la ausencia de condiciones desde el Estado para la participación política, democrática e ideológica de los ciudadanos (Sacipa, Tovar, Sarmiento, Gómez, \& Suárez, 2013), particularmente en un país como Colombia en el que se reconoce que el conflicto armado se remonta a la época de la violencia, que en un primer momento se caracterizó por la persecución a la oposición, impidiendo su participación política de una manera democrática en el contexto nacional, así como en otros momentos de la historia en los que se han vulnerado los derechos democráticos de diferentes movimientos sociopolíticos divergentes y variados.

\section{Violencia}

La única claridad que podemos encontrar frente a la violencia es que no existe un consenso entre las diferentes conceptualizaciones y posturas que la abordan, quizás esto sucede porque en estas se busca intentar abarcar todas las formas posibles de violencia (Sémelin, 1983, citado por Blair, 2009) y los contextos donde ésta emerge, más no su funcionalidad en las relaciones humanas. Si la violencia se hunde profundamente en sus raíces desde la cultura al haber existido siempre en la vida social (Pessin, 1979, citado por Blair, 2009), el debate teórico avanza desde diferentes disciplinas, epistemologías y perspectivas donde se busca una conceptualización más precisa y unificada donde parecería, qué se deja de lado la idea de que la comprensión de este fenómeno también es una construcción social que podría verse como un diálogo dinámico.

La violencia, desde una dimensión política, se constituye como el medio para dominar a otros, teniendo como finalidad establecer, mantener o cambiar un determinado orden social (Barreto \& Borja, 2007). Según Aróstegui (1994, citado por Barreto \& Borja, 2007), la violencia es una acción o situación que se genera siempre y se cualifica de manera exclusiva en el centro de un conflicto. En ese sentido, este tipo de acciones o situaciones requieren de una justificación, Martín-Baró (2003) que permitan asumir las consecuencias psicológicas, políticas y sociales, incluso, la deslegitimación del grupo contrario (Barreto \& Borja, 2007), a través desde la deshumanización y des-personificación de las víctimas, la existencia de una confianza ciega en la institución o grupo de pertenencia, una aparente responsabilidad compartida por el colectivo y la tecnificación de las acciones de guerra (Duster \& Fanon, s.f, citado por Martín-Baro, 2003).

En Colombia, según el Grupo de Memoria Histórica (2013), la violencia contra la integridad física es el rasgo distintivo de los grupos paramilitares, mientras que la violencia contra la libertad y la disputa por bienes materiales caracteriza las acciones de los grupos guerrilleros. La violencia ejercida por la fuerza pública, se centraría en detenciones arbitrarias, torturas, asesinatos 
selectivos, desapariciones forzadas y del uso desmedido y desproporcionado de la fuerza. Así, nuestro devenir histórico ha implicado la multivariedad de la violencia: violencias (política, socioeconómica, física, sobre los territorios, socio-cultural) que necesariamente deben ser comprendidas desde la multicausalidad y la experiencia humana de quienes las vivieron (Villaveces, 1996, citado por Blair, 2009, p. 25), más allá de su descripción como fenómeno (Blair, 2009).

Así mismo la experiencia de las personas o grupos específicos debe comprenderse desde el marco social, en donde el énfasis debe realizarse sobre una revisión de la propia estructura histórica del contexto. Este carácter histórico es comprendido por MartínBaró (2003) como un presupuesto de un proceso que se dada en espiral, es decir que a lo largo de la historia, la violencia social surge como un proceso autónomo que dinamiza y multiplica los actos violentos, en ese sentido se pueden identificar los siguientes elementos la estructura formal del acto, la ecuación personal, el contexto posibilitador y el fondo ideológico (Martín-Baró, 2003) como elementos característicos de dicho proceso. En estas cuatro categorías, la estructura formal del acto es su operacionalización y la forma en la cual se ejecuta, la ecuación personal se refiere a los elementos del acto de violencia explicables solamente por las características particulares de las personas que lo llevan a cabo, el contexto posibilitador es en el que se desenvuelve un individuo, el cual lo conduce a actuar o no de forma violenta y se divide en contexto mediato (social) e inmediato (situacional) y por último el fondo ideológico es referido a una realidad social configurada por unos intereses en base a un determinado pensamiento.

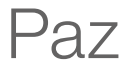

Mesa (2008) documenta la diferenciación realizada por autores como (Galtung, 1969, citado por Mesa 2008) entre la comprensión negativa de la paz y su enfoque positivo. La primera corresponde a la ausencia de confrontación bélica, mientras que la segunda inaugura un debate respecto a los elementos necesarios para construir una cultura de paz sostenible, donde realmente sean asegurados los derechos humanos, y el cuidado y respeto del medio ambiente. Por otra parte, el concepto de construcción de paz se ha descentrado del contexto de post-guerra para considerar escenarios de prevención, gestión y rehabilitación. (UNESCO, 1999), define paz como la movilización que permite superar todas las expresiones de violencia directa, cultural o estructural; también la cultura de paz se puede comprender desde la acción que busca legitimar una convivencia sana donde se haga evidente la superación de la inequidad como una forma de violencia estructural (Barreto \& Borja, 2007), es más asumiendo que la cultura de paz supone abordar la multicausalidad de los conflictos (Mesa, 2008) entendiendo qué los discursos construidos por grupos sociales son tan importantes como los cambios estructurales que la sociedad necesita.

Aun cuando por diversos factores se ha consolidado una cultura pasiva de participación política de la ciudadanía colombiana, se registran formas de resistencia cultural y política cotidianas que se han dado para contrarrestar la violencia y mantener 
una autonomía relativa frente a los actores armados (Alzate, 2010). Por otra parte, las iniciativas colectivas y masivas han movilizado transformaciones hacia la democracia y un empoderamiento de la sociedad civil respecto a su realidad sociopolítica. Lo anterior se observa en la documentación que CAVIDA (2002, p.16) realiza respecto a la posición asumida por la población civil tras la Operación Génesis en el Urabá chocoano:

Las lecturas más allá de lo que aparece, las causas que se ocultan, la exclusión, la marginalidad, el hambre, la miseria... dejan evidente que la población civil es terca, es creativa, es constructora de iniciativas que miran más allá de lo que los investigadores sociales hablan o dicen de la realidad, de esta guerra... hablan de epopeyicas populares, de sueños de sociedad posible distintos, de ideas de progreso cualitativamente distintas a las del poder.

Parecería que la comprensión que se tiene de la paz depende del territorio que se habita, pero sobre todo, de la experiencia de vida en relación con el conflicto armado. El relato anteriormente citado contrasta con la investigación realizada por Sacipa (2005) con ciudadanos de Bogotá: los significados de paz de los bogotanos no están vinculados con la reconciliación y la participación política. Para los Bogotanos, la paz, como un fenómeno lejano, está en manos de otros y no es responsabilidad propia, asociada a la comprensión negativa de la paz como ausencia de violencia directa y de conflicto bélico; también se retoman la armonía familiar y la paz espiritual como elementos necesarios para la paz.

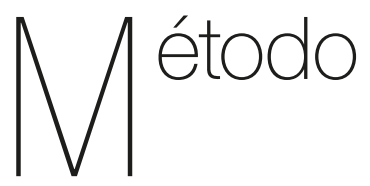

\section{Diseño}

Esta investigación asume un enfoque cualitativo hermenéutico, cuyo objetivo es descubrir e interpretar los significados de las palabras conservando su singularidad en el contexto del cual forman parte (Dilthey, 1900; Schleiermacher, 1967, citados por Martínez, 2006). La hermenéutica es la herramienta que conecta lo hablado por cada uno de los actores con sus experiencias e historias de vida, que a su vez son mediadas por el contexto histórico, social, cultural, económico y político de desarrollo de cada sujeto.

El construccionismo social, como punto de partida epistemológico de esta investigación, es comprendido como una propuesta crítica dentro de la psicología social que cuestiona políticamente a las tradicionales perspectivas de la disciplina psicológica (Ibáñez, 2003), sosteniendo que el conocimiento es adquirido a través del involucramiento con el mundo y cómo se atribuyen significados a las percepciones de él: moldeamos al mundo y éste nos moldea. Desde este enfoque, se sostiene que es en las interacciones relacionales, mediadas por el lenguaje, donde son creados, modificados e institucionalizados los fenómenos sociales que cotidianamente hacen parte de nuestra realidad (Cisneros \& Faux, 2008).

\section{Participantes}

Se realizó un muestreo intencionado luego de identificar las necesidades 
de información en las primeras fases de un estudio (Martín-Crespo \& Salamanca, 2007). Dentro de los criterios de inclusión de los participantes se estableció que fueran civiles no afectados directamente por el conflicto armado interno colombiano, que cumplieran el requisito de la mayoría de edad (18 años) y que pertenecieran a contextos de urbano o rural por un periodo superior a seis meses. El contexto rural estaría relacionado con procesos territoriales muy diversos, cuya construcción social está determinada por la relación con el entorno natural y por la baja densidad poblacional (Osorio, 2005), ,sin desconocer que en términos pragmáticos la frontera ruralurbana es cada vez más difusa en términos relacionales y actividades económicas Así mismo, el contexto urbano se podría comprender como el lugar adherido a una jurisdicción política, donde el tamaño de la población podría abarcar acerca desde 2000 habitantes, específicamente debe estar entre un rango de personas $200 \mathrm{y}$ 50.000. La estructuración territorial del contexto urbano se determinaría además por condiciones económicas y la pavimentación de sus vías (UNICEF, 2012). La Tabla 1 presenta las principales características sociodemográficas de los 37 participantes.

\section{Instrumento}

El estudio empleó el grupo focal como técnica de recolección de datos, en una modalidad de entrevista grupal abierta y semi-estructurada, que toma forma de conversación grupal, diferenciándose de una conversación coloquial la medida en la que el investigador planteó previamente las temáticas que se abordaron, de acuerdo con los propósitos de la investigación. Los grupos focales requieren de procesos de interacción, discusión y elaboración de acuerdos dentro del grupo acerca de las temáticas propuestas por el investigador (Aigneren, 2009), buscando comprender cómo los participantes elaboran grupalmente su realidad desde sus particularidades socio-histórico-demográficas.

Para llevar a cabo la investigación se utilizaron principalmente dos instrumentos. En la fase 1 (Revisión bibliográfica de los conceptos violencia, conflicto armado y paz y su relación) se hizo uso de un formato general para la construcción de los Resúmenes Analíticos Especializados teniendo en cuenta que, como lo afirma Landazábal, Páez y Ballesteros (2013), este debe ser un escrito con un formato estructurado en el cual se pretende reducir al máximo y con la mayor precisión un tema específico y obtener una visión general del tema, así como una comprensión integral. En la fase 2 (realización de los grupos focales con los diferentes grupos poblacionales), se construyó una guía semiestructura que abordo 20 preguntas distribuidas en los focos nombrados anteriormente.

\section{Análisis de la información}

La información recolectada fue analizada a través de un análisis de contenido. Según Abela (2003), esta técnica de interpretación permite consolidar una lectura de los datos desde dos de sus dimensiones: expresiva y latente, siendo la primera, lo que el autor quiere decir y la segunda aquelloa que el autor puede decir sin necesidad de pretenderlo (es decir, de manera implícita y no intencional), captando de esta forma el contenido y el significado de lo expresado por los participantes. E 
análisis de contenido diferencia y resalta la relevancia del texto y el contexto como elementos constituyentes de la interpretación de un fenómeno.

\section{Procedimiento}

El presente estudio se desarrolló entre mediados del año 2014 y mediados del año 2015 a partir del siguiente procedimiento:

1. La Revisión bibliográfica de los conceptos violencia, conflicto armado $y$ paz y su relación, se consolidó desde el análisis bibliográfico de dieciocho documentos, a partir de los cuales se realizaron Fichas de Resumen Analítico Especializado (RAE).

2. Se procedió con la elaboración de categorías de análisis a partir de los resultados obtenidos en la primera fase de revisión bibliográfica. Se definieron tres focos: influencia histórico cultural en la transformación de los significados (los procesos y contextos culturales y sociales), sentidos de los significados (los criterios, generalmente implícitos, empleados por los sujetos para delimitar y diferenciar los conceptos) y eventos (experiencias y sucesos específicos en relación a los significados).

3. Acercamiento a las organizaciones $y$ personas participantes en los grupos focales y sus contextos de acción y territorios. En esta fase se incluyen las gestiones correspondientes al contacto con las poblaciones, el envío de cartas, la disposición del espacio para realizar el grupo focal, el desplazamiento de los investigadores, entre otros aspectos logísticos.

4. La Recolección de datos a través de la realización de los grupos focales.
Luego del acercamiento a los diferentes contextos rurales y urbanos para gestionar la participación de los ciudadanos, se establecieron citas con las diferentes poblaciones y se dio inició a la realización de los grupos focales. Dicha realización, que tuvo una duración cercana a una hora, incluyó el diligenciamiento del consentimiento informado por cada participante.

5. En el Análisis de información y consolidación de conclusiones y aportes de la investigación, la información recolectada en cada grupo focal fue analizada a partir una matriz de análisis, donde se retomaron las categorías abordadas en los guiones de los grupos focales. Se diseñaron algunas subcategorías emergentes: dentro del primer foco (influencia históricocultural en la transformación de los significados), se conformaron las subcategorías paz, violencia, conflicto, impacto de la región en compresiones e impacto de los medios de comunicación. El segundo foco (sentidos), abarcó las subcategorías violencia, paz y conflicto, reconocidas a partir de tres dimensiones: criterios para delimitar el concepto, actores involucrados en el fenómeno y función de éste en la realidad colombiana. El último foco (eventos) retoma las subcategorías situaciones y personas significativas en historia de vida con relación a la realidad sociopolítica colombiana y acciones personales en la construcción de paz o el mantenimiento de conflicto. Este análisis de contenido permitió construir una comprensión detallada e interpretativa de las transcripciones, que posteriormente dio lugar a la construcción de un análisis general contrastando la información de los diferentes grupos focales. 


\section{Resultados}

\section{La Tabla 1 presenta las principales características sociodemográficas de los participantes.}

Tabla 1.

Características Sociodemográficas de los Participantes

\begin{tabular}{|c|c|c|c|c|c|}
\hline Contexto & $\begin{array}{l}\text { Madres comunita- } \\
\text { rias de la Localidad } \\
\text { de Bosa, Bogotá }\end{array}$ & $\begin{array}{l}\text { Estudiantes Univer- } \\
\text { sitarios de Bogotá }\end{array}$ & $\begin{array}{l}\text { Ciudadanos de } \\
\text { Fusagasugá }\end{array}$ & $\begin{array}{l}\text { Ciudadanos del } \\
\text { Municipio de } \\
\text { Villapinzón }\end{array}$ & $\begin{array}{c}\text { Ciudadanos del } \\
\text { Municipio de Mosquera }\end{array}$ \\
\hline & Urbano & Urbano & Urbano & Rural & Rural \\
\hline $\begin{array}{c}\text { Total de } \\
\text { participantes }\end{array}$ & 6 & 5 & 7 & 9 & 10 \\
\hline $\begin{array}{l}\text { Cantidad de mu- } \\
\text { jeres y hombres }\end{array}$ & 6 mujeres & 1 mujer y 4 hombres & $\begin{array}{l}4 \text { mujeres y } 3 \\
\text { hombres }\end{array}$ & $\begin{array}{c}7 \text { mujeres y } 2 \\
\text { hombres }\end{array}$ & 4 hombres y 6 mujeres \\
\hline $\begin{array}{c}\text { Rango de } \\
\text { edades (años) }\end{array}$ & $40-70$ & $20-30$ & $40-70$ & $20-70$ & $20-70$ \\
\hline $\begin{array}{l}\text { Estratos So- } \\
\text { cioeconómicos }\end{array}$ & $\begin{array}{l}5 \text { personas en el } \\
\text { estrato } 2 \text { y una per- } \\
\text { sona en el estrato } 3\end{array}$ & $\begin{array}{l}2 \text { personas en el } \\
\text { estrato } 1,2 \text { perso- } \\
\text { nas en el estrato } \\
2 \text { y } 1 \text { persona en } \\
\text { el estrato } 3\end{array}$ & $\begin{array}{c}3 \text { personas en el es- } \\
\text { trato } 3,2 \text { personas } \\
\text { en el estrato } 4, \text { y } 1 \\
\text { persona en el estra- } \\
\text { to } 2.1 \text { participante } \\
\text { no reporto estrato }\end{array}$ & $\begin{array}{l}6 \text { personas en el } \\
\text { estrato } 2 \text { y } 3 \text { perso- } \\
\text { nas en el estrato } 1\end{array}$ & $\begin{array}{l}2 \text { personas el estrato } 1 \text {, } \\
4 \text { personas en el estrato } \\
3,2 \text { personas en el } \\
\text { estrato } 2 \text { y } 1 \text { perso- } \\
\text { na en el estrato } 4\end{array}$ \\
\hline $\begin{array}{l}\text { Nivel de } \\
\text { estudios }\end{array}$ & $\begin{array}{l}4 \text { personas en } \\
\text { nivel técnico, } 1 \text { en } \\
\text { nivel de secundaria } \\
\text { y } 1 \text { persona en } \\
\text { nivel universitario }\end{array}$ & $\begin{array}{l}\text { Las } 5 \text { personas } \\
\text { se encuentran en } \\
\text { nivel de estudios } \\
\text { universitario }\end{array}$ & $\begin{array}{l}5 \text { personas en nivel } \\
\text { de secundaria, } 1 \\
\text { persona en primaria } \\
\text { y } 1 \text { persona en nivel } \\
\text { complementario } \\
\text { al universitario }\end{array}$ & $\begin{array}{l}6 \text { personas en } \\
\text { nivel de primaria, } 2 \\
\text { personas en nivel } \\
\text { de secundaria y } 1 \\
\text { persona en nivel } \\
\text { universitario }\end{array}$ & $\begin{array}{l}1 \text { persona en nivel de } \\
\text { primaria, } 1 \text { persona en } \\
\text { secundaria, } 2 \text { personas } \\
\text { en universitario, } 1 \text { en } \\
\text { tecnólogo y } 4 \text { en comple- } \\
\text { mentario al universitario }\end{array}$ \\
\hline $\begin{array}{l}\text { Creencias } \\
\text { religiosas }\end{array}$ & $\begin{array}{l}5 \text { personas son } \\
\text { cristianas-católicas } \\
\text { y } 1 \text { persona es } \\
\text { evangélica }\end{array}$ & $\begin{array}{l}4 \text { personas son cris- } \\
\text { tianas - católicas y } 1 \\
\text { persona es de otra. }\end{array}$ & $\begin{array}{l}5 \text { personas son } \\
\text { cristianas-católicas } \\
\text { y dos personas } \\
\text { evangélicos }\end{array}$ & $\begin{array}{l}9 \text { personas son } \\
\text { cristianas-católicas }\end{array}$ & No responde \\
\hline $\begin{array}{l}\text { Tiempo de resi- } \\
\text { dencia actual }\end{array}$ & $\begin{array}{l}\text { Todos han estado } \\
\text { más de } 10 \text { años }\end{array}$ & $\begin{array}{l}4 \text { personas han } \\
\text { estado más de } 10 \\
\text { años y } 1 \text { persona } \\
\text { de ha estado de } \\
\text { 1- a } 5 \text { años }\end{array}$ & $\begin{array}{l}5 \text { personas han } \\
\text { estado más de } 10 \\
\text { años, } 1 \text { persona de } \\
1 \text { a } 5 \text { años y } 1 \text { per- } \\
\text { sona de } 5 \text { a } 10 \text { años }\end{array}$ & $\begin{array}{c}8 \text { personas han } \\
\text { estado más de } 10 \text { y } \\
1 \text { persona ha estado } \\
\text { de } 6 \text { meses a } 1 \text { año }\end{array}$ & $\begin{array}{l}2 \text { personas viven desde } \\
\text { hace } 5 \text { a } 10 \text { años } \\
4 \text { personas hace } \\
\text { más de } 10 \text { años y dos } \\
\text { personas de } 1 \text { a } 5 \text { años }\end{array}$ \\
\hline $\begin{array}{l}\text { Participación } \\
\text { en institución } \\
\text { o movimiento }\end{array}$ & $\begin{array}{l}\text { Todas participan } \\
\text { en el ICBF }\end{array}$ & $\begin{array}{c}\text { Ninguna persona } \\
\text { participa }\end{array}$ & $\begin{array}{l}\text { Solo } 1 \text { persona } \\
\text { participa pero no es- } \\
\text { pecifica a cual movi- } \\
\text { miento hace parte. }\end{array}$ & $\begin{array}{l}\text { Sólo } 1 \text { persona par- } \\
\text { ticipa (en el Comité } \\
\text { de estratificación } \\
\text { socioeconómico } \\
\text { del Municipio) }\end{array}$ & $\begin{array}{c}3 \text { personas participan en } \\
\text { la Alcaldía de Municipal }\end{array}$ \\
\hline $\begin{array}{l}\text { Ocupaciones } \\
\text { actuales }\end{array}$ & $\begin{array}{l}\text { Educadoras y ma- } \\
\text { dres comunitarias }\end{array}$ & $\begin{array}{l}\text { Empleados y } \\
\text { estudiantes (2) } \\
\text { y personas son } \\
\text { universitarios (3) }\end{array}$ & $\begin{array}{l}\text { Pensionados (3), } \\
\text { comerciantes } \\
\text { (2), empleada de } \\
\text { servicios públicos } \\
\text { de la ciudad (1) y } \\
\text { encargada del aseo } \\
\text { de su hogar (1) }\end{array}$ & $\begin{array}{l}\text { Amas de Casa } \\
\text { (4), ganadero (1), } \\
\text { agricultor (1), Vende- } \\
\text { doras por catálogo } \\
\text { (2) y trabajadora } \\
\text { doméstica (1) }\end{array}$ & $\begin{array}{c}\text { Empleada (1), Psicó- } \\
\text { logo (1), ama de casa } \\
\text { (1), empleada - } \\
\text { Estudiante (1), Medica } \\
\text { veterinaria (1), contratista } \\
\text { del SENA (1), empleados } \\
\text { públicos (2) y funcio- } \\
\text { nario de ICBF (1) }\end{array}$ \\
\hline
\end{tabular}




\section{Categoría Influencia histórico-cultural en la transformación de los significados}

En relación al impacto que ha tenido el contexto histórico-cultural colombiano en la construcción de significados en torno a las categorías violencia, conflicto armado y paz, se encontró estos están permeados por algunos aspectos políticos, tales como la implementación de la legislación consignada en la constitución política del país, la vulneración de los derechos humanos, la invisibilización de los actos que los violentan y la corrupción de diferentes sectores y actores políticos, tales aspectos fueron reconocidos como una dificultad parapara la construcción de la paz en Colombia. Por otro lado, se reconoce que los contextos familiar y educativo están directamente involucrados en lo que se refiere a la violencia y la construcción de paz, siendo estos desde los cuáles se gestan acciones significativas para la manutención o finalización del conflicto armado. Incluso frente a esta última afirmación se reconoce que cualquier tipo de cambio a nivel social no se da de manera inmediata, sino dentro de un mediano o largo plazo.

Se reconoce que la violencia es un fenómeno que se manifiesta en diferentes instancias, desde aquellas que involucran la cotidianidad de los colombianos, hasta aquellas más complejas que no se ven con tanta frecuencia e involucran situaciones sociales, políticas a nivel nacional. Se identifican diferentes maneras de violentar a otros a través de distintas acciones, que varían de acuerdo al contexto en el que surgen: en las zonas rurales la violencia estaría determinada por intereses políticos y económicos (ej. el desplazamiento forzado como una manera en la que se obliga a las poblaciones a abandonar su territorio para cederlo a grupos armados), mientras que en las urbes la violencia surge en relación a otro tipo de problemáticas sociales estructurales que desencadenan expresiones de violencia social a través de la criminalidad común (ej. robos a mano armada, accidentes de tránsito, injusticia social).

Las personas manifiestan que los actos de violencia en las zonas rurales son invisibilizados ante la escasa difusión que permite visibilizar lo que ocurre en el campo, lo que consideran como una manera de ocultar la realidad y pasar de manera inadvertida lo que ocurre en estos contextos. Por otro lado en las urbes, se piensa que los castigos a quienes cometen actos violentos no son justos y aun si lo fuesen, por lo general aquellas personas que cuentan con gran cantidad de recursos económicos logran evadir las penas que les son conferidas por sus crímenes, además de ello se reconoce que muchas veces las autoridades competentes como la fuerza pública y las entidades judiciales no cumplen su labor punitiva con este tipo de personas pues en cierto sentido, así lo expresan los participantes cuando dicen "atrapan a esos vándalos y al rato los dejan ir libres".

Se encuentra que los participantes reconocen que hubo una transformación en los valores sociales bajo la expresión coloquial "se perdió el respeto", es decir que se dada una manera diferente de construir relaciones humanas, 
de carácter más permisivo, niveles de proximidad y confianza mayores, donde no se guarda la misma distancia entre los sujetos, de este modo es permitido afectar de una manera más clara el espacio del otro, así como atentar contra su integridad y dignidad. Este cambio de valores desencadena diferentes tipos de violencia reconocidos por los participantes, tales como la violencia intrafamiliar, violencia mediática, entre otros, como una manera de evidenciar una transformación en la escala de valores sociales bajo la cual se organizan las interacciones de los sujetos, como se mencionó anteriormente. La violencia sería para los participantes un fenómeno constitutivo de la historia del país que ha logrado transformar las dinámicas relacionales de los colombianos. Dicho carácter histórico se vincula a acontecimientos históricos como la lucha por el poder entre el los partidos liberal y conservador y el surgimiento de grupos armados con intereses sociopolíticos que han perseguido transformaciones para el país.

Respecto al impacto de la información sociodemográfica de los municipios en donde los participantes habitan y sus comprensiones construidas de los fenómenos de interés ;;ellos visibilizan actores particulares del conflicto armado en relación a experiencias específicas ocurridas en sus territorios de residencia que son Villapinzón, Fusagasugá, Mosquera y Bogotá, aunque dichas experiencias se profundizan en la categoría eventos, en donde es importante también resaltar que aquellas experiencias se narran como parte de los relatos colectivos de las comunidades de los participantes. Así mismo aunque los participantes no sean directamente afectados por el conflicto armado, cada región vive la violencia y el conflicto con un matiz particular, el hurto, asesinatos, riñas o peleas, como actos de violencia, generan en los participantes sensaciones de temor, miedo, zozobra, expectativa, angustia y desolación, reconociendo que, como se dijo anteriormente, estos fenómenos son identificados como parte de la historia colombiana de nuestro país.

Adicionalmente, los participantes mencionan que saben y conocen del conflicto a través de "familiares, vecinos, conocidos" y medios de comunicación. Frente a estos últimos, se hace mención de la mediatización de la información y la influencia de estos en la comprensión que tienen los ciudadanos de la realidad del país, reconociendo a la prensa, la radio, el internet y la televisión como las principales herramientas de difusión de la información. Los participantes afirman que en los medios de comunicación existe un interés de fondo para manipular y beneficiar intereses particulares, vinculando principalmente al Estado. Se expresa desconfianza e incertidumbre frente a los mensajes transmitidos por la televisión, identificándolos como otro de los factores que generan y perpetúan la violencia en el país, asumiendo que estos medios también cumplen una función en la socialización de las nuevas generaciones en desarrollo. En los contextos rurales se identifica una mayor dificultad al acceso de información concerniente a la realidad sociopolítica del país herramientas como el internet, recurso con el que se da un limitado acceso que permita a las personas informarse con mayor amplitud acerca del panorama de lo que sucede en el territorio colombiano. 


\section{Categoría Sentidos}

Los sentidos, entendidos como los criterios que los participantes emplearon en sus discursos para delimitar y diferenciar los conceptos de violencia, conflicto y paz, fueron reconocidos a través de tres subcategorías: criterios para delimitar cada uno de los tres fenómenos sociales, actores que participan en cada uno de ellos y su función y naturaleza en la realidad colombiana.

Si bien Tabla 2 presenta a profundidad los resultados de la categoría Sentidos, se destaca que frente a los criterios para delimitar el concepto de violencia los diferentes grupos de participantes propusieron categorizaciones de esta y escenarios donde se manifiesta, que van desde su origen en el sistema familiar, hasta las instituciones políticas y sociales colombianas. En relación con el conflicto, los participantes retomaron sus vivencias cotidianas para definirlo, construyendo una compresión que involucra, pero también sobrepasa, el histórico conflicto armado interno colombiano. La violencia fue comprendida como una solución negativa de un conflicto, constituido por diferencias en la forma de pensar y percibir una situación o evento concretos. Respecto a los criterios para delimitar el concepto de paz, los diferentes grupos de participantes convergieron en que su principal característica es ser proceso cotidiano.

Dentro de la subcategoría de Actores, los participantes identificaron que los grupos armados ilegales (guerrillas y grupos paramilitares), el Estado y la Fuerza Pública son los principales protagonistas de la violencia y el conflicto. En estos dos fenómenos sociales se reconoció que la población civil era la principal afectada, aunque en la comprensión del conflicto emergieron algunos actores diferenciales, que se profundizan en la Tabla 2. Desde la comprensión de los participantes, los actores implicados en los procesos de construcción de paz son "todos", haciendo referencia a los ciudadanos colombinos, aunque sobresalen los roles que desempeñan la familia, los medios de comunicación y las instituciones educativas y religiosas como contextos de socialización que posibilitan la transmisión de valores de convivencia social y democrática.

Finalmente, respecto a la subcategoría Función y naturaleza del fenómeno en la realidad colombiana, los participantes expresaron que la violencia es un mecanismo de acceso al poder económico y político. Los intereses económicos y políticos, aunados a diferencias ideológicas, fueron también identificados como el trasfondo del conflicto armado colombiano; la guerra se caracterizó como un negocio y se cuestionó un genuino interés de los actores armados por culminarla. En relación con la naturaleza de la paz en Colombia, los participantes manifestaron explícitamente incredulidad frente a los vigentes diálogos de paz con las FARC que se realizan en la Habana, Cuba, afirmando que no incluyen factores como la pobreza y la mala distribución de los recursos, identificándose una desarticulación notable entre las acciones políticas (que fueron comprendidas como lejanas) y la realidad de los ciudadanos. 
Tabla 2

Resultados Categoría Sentidos

\begin{tabular}{|c|c|c|c|}
\hline & Violencia & Conflicto & Paz \\
\hline $\begin{array}{c}\text { Criterios para } \\
\text { delimitar el } \\
\text { concepto }\end{array}$ & $\begin{array}{l}\text { La población civil rural de Villapinzón } \\
\text { realiza una distinción entre diversos } \\
\text { tipos de violencia, haciendo un } \\
\text { énfasis en la violencia ejercida por } \\
\text { la guerrilla (“demasiado violenta” y } \\
\text { negativa). Los jóvenes universitarios } \\
\text { también proponen tipos de violencia } \\
\text { como la urbana, señalando el papel } \\
\text { activo que todos tenemos en ella } \\
\text { (aun indirectamente). En la población } \\
\text { de Bosa, las madres comunitarias } \\
\text { también distinguen tipos de violencia: } \\
\text { la violencia física, verbal, psicoló- } \\
\text { gica, de género, social y familiar. } \\
\text { Los ciudadanos de Fusagasugá } \\
\text { referencian también la violencia } \\
\text { física, a la cual se llega cuando existe } \\
\text { intolerancia por parte de las personas } \\
\text { involucradas en un conflicto. }\end{array}$ & $\begin{array}{l}\text { Los participantes de Villapinzón y Fusa- } \\
\text { gasugá refieren que un conflicto puede } \\
\text { ser positivo o negativo, diferenciándose } \\
\text { de la violencia en que esta es una } \\
\text { forma de resolverlo desde "agresio- } \\
\text { nes y golpes" (un conflicto podría } \\
\text { generar violencia). Los participantes de } \\
\text { Fusagasugá convergen en la idea de } \\
\text { que la naturaleza positiva o negativa } \\
\text { del conflicto dependerá del grado de } \\
\text { tolerancia que tengan las personas. } \\
\text { Los participantes de Mosquera, Bosa } \\
\text { y los Estudiantes Universitarios tienden } \\
\text { a enmarcar la definición de conflicto } \\
\text { desde las características históricas del } \\
\text { conflicto armado interno de Colombia. }\end{array}$ & $\begin{array}{l}\text { La población rural de Villapinzón } \\
\text { reconoce que acciones como el } \\
\text { "saludar", el "ayudar" y la cercanía } \\
\text { con Dios son necesarias para paz. } \\
\text { Para los estudiantes universitarios } \\
\text { la paz implica y se relaciona con la } \\
\text { felicidad: "alguien es feliz por simple- } \\
\text { mente tener la paz". Otras acciones } \\
\text { del día a día que contribuyen a la } \\
\text { construcción de paz son la toleran- } \\
\text { cia, el respeto y la igualdad y la } \\
\text { educación. Si bien los participantes } \\
\text { de Fusagasugá también resaltan a la } \\
\text { familia como escenario de construc- } \\
\text { ción de paz, comprenden que para } \\
\text { su real consolidación es necesaria la } \\
\text { garantía del bienestar de todos los } \\
\text { colombianos desde la consecu- } \\
\text { ción de los derechos humanos. }\end{array}$ \\
\hline Actores & $\begin{array}{l}\text { Los actores violentos identificados } \\
\text { son las organizaciones alzadas en } \\
\text { armas (la guerrilla, paramilitares, } \\
\text { fuerzas armadas y BACRIM y los ciu- } \\
\text { dadanos). Las madres comunitarias } \\
\text { de Bosa afirman que los ciudadanos } \\
\text { son los más afectados por la violen- } \\
\text { cia. La población de Fusagasugá no } \\
\text { se refiere al conflicto armado como el } \\
\text { único contexto violento, la educación, } \\
\text { el gobierno, el estado y la familia } \\
\text { son también escenarios cotidianos } \\
\text { violentos. En concordancia con esto, } \\
\text { los estudiantes universitarios y la po- } \\
\text { blación rural de Villapinzón describen } \\
\text { que el actor violento es cualquiera } \\
\text { que realice una acción negativa en } \\
\text { contra de otro de forma intencionada. }\end{array}$ & $\begin{array}{l}\text { Los principales actores del conflicto ar- } \\
\text { mado colombiano identificados son las } \\
\text { guerrillas (se mencionan al ELN, FARC } \\
\text { Y M-19), el estado y sus fuerzas arma- } \\
\text { das, altos mandatarios del gobierno (en } \\
\text { relación a la corrupción), las BACRIM, } \\
\text { los paramilitares, la población civil (se } \\
\text { mencionan indígenas, campesinos, } \\
\text { "falsos positivos de Soacha" y niños } \\
\text { como principales afectados) y medios } \\
\text { de comunicación. Los participantes de } \\
\text { Bosa identifican que la población civil } \\
\text { es la mayormente afectada por el con- } \\
\text { flicto armado interno colombiano. Los } \\
\text { únicos participantes que diferencian } \\
\text { entre "víctimas" y "victimarios" son los } \\
\text { participantes de Mosquera, quienes } \\
\text { también manifiestan la posibilidad de } \\
\text { que los guerrilleros y paramilitares sean } \\
\text { comprendidos como víctimas, recono- } \\
\text { ciendo que son "esclavos de la guerra". } \\
\text { Los estudiantes universitarios son los } \\
\text { únicos que se sumen como afectados } \\
\text { directamente por el conflicto, manifes- } \\
\text { tando que sus cotidianidades son atra- } \\
\text { vesadas por las dinámicas de la guerra. }\end{array}$ & $\begin{array}{l}\text { Todos los participantes convergen } \\
\text { en la idea de que es de "todos" la } \\
\text { responsabilidad de la construcción } \\
\text { de paz. Actores que se resaltan } \\
\text { específicamente son los medios de } \\
\text { comunicación como socializadores } \\
\text { de la realidad (participantes de } \\
\text { Villapinzón), las "familias colombia- } \\
\text { nas" como transmisoras de valores } \\
\text { de convivencia social (participantes } \\
\text { de Mosquera), los educadores, estu- } \\
\text { diantes, la Iglesia (no se especifica } \\
\text { cuál), las alcaldías, las universida- } \\
\text { des y las comunidades en general } \\
\text { (Madres comunitarias de Bosa). Los } \\
\text { Estudiantes Universitarios reconocen } \\
\text { que la cultura y la educación son } \\
\text { herramientas de construcción de } \\
\text { paz como un proceso continuo. Los } \\
\text { participantes de Villapinzón añaden } \\
\text { que la participación de todos en la } \\
\text { construcción de paz serviría para } \\
\text { reconstruir el tejido social de un país } \\
\text { que se encuentra fragmentado. }\end{array}$ \\
\hline $\begin{array}{c}\text { Función y } \\
\text { naturaleza } \\
\text { del fenómeno } \\
\text { en la realidad } \\
\text { colombiana }\end{array}$ & $\begin{array}{l}\text { Se ubica dentro de las naturalizada } \\
\text { búsqueda del poder en las relaciones, } \\
\text { que ha implicado el no respeto por la } \\
\text { integridad de las otras personas; de } \\
\text { la cultura del día a día ya hace parte } \\
\text { el hecho de que "sobrevive el más } \\
\text { fuerte". Las madres comunitarias } \\
\text { de Bosa proponen soluciones para } \\
\text { hacer frente a la violencia como di- } \\
\text { fundir el respeto por la vida, generar } \\
\text { acuerdos para que acabe el conflicto, } \\
\text { generar más empleos y reivindicar } \\
\text { la importancia de los campesi- } \\
\text { nos.. La población de Fusagasugá } \\
\text { expresa otro factor que influye en el } \\
\text { accionar de acciones violentas: la } \\
\text { falta de organización del gobierno }\end{array}$ & $\begin{array}{l}\text { Los participantes convergen en la idea } \\
\text { de que en el trasfondo del conflicto } \\
\text { armado colombiano hay intereses } \\
\text { económicos y políticos. Se referencia } \\
\text { que las motivaciones ideológicas de } \\
\text { las guerrillas ya no hacen parte de } \\
\text { sus principales objetivos actuales. En } \\
\text { reiteradas ocasiones se hace énfasis } \\
\text { en el narcotráfico y la apropiación de } \\
\text { tierras como factores que mantienen } \\
\text { el conflicto armado. Se identifica } \\
\text { que la participación de los grupos } \\
\text { armados (especialmente las Fuerzas } \\
\text { Armadas Estatales) en la guerra no } \\
\text { está dirigida a culminar el conflicto } \\
\text { sino, por el contrario, a perpetuarlo. }\end{array}$ & $\begin{array}{l}\text { Los participantes de Mosquera } \\
\text { resaltan nuevamente que la paz debe } \\
\text { ser construida desde las familias. } \\
\text { Los Estudiantes universitarios y las } \\
\text { Madres Comunitarias de Bosa también } \\
\text { convergen en comprensión de que } \\
\text { más allá de identificar intereses para } \\
\text { la construcción de paz, la reciente } \\
\text { historia colombiana se configura desde } \\
\text { intereses para mantener la guerra y el } \\
\text { conflicto armado. Los participantes de } \\
\text { Fusagasugá introducen como tema de } \\
\text { debate al post-conflicto, reconociendo } \\
\text { la posibilidad de futuras nuevas formas } \\
\text { de violencia, asumiendo los posibles } \\
\text { retos futuros de la convivencia en las } \\
\text { ciudades con las personas que se des- } \\
\text { movilicen de grupos armados ilegales. }\end{array}$ \\
\hline
\end{tabular}




\section{Categoría Eventos}

Las situaciones vividas por las personas son muy importantes al momento de dar un sentido a la comprensión respecto a la realidad sociopolítica de Colombia; las construcciones que se generan obedecen a una experiencia directa o un algún relato contado por alguna persona cercana. La investigación evidencia que el contexto y rol particular en el que se desenvuelven las personas en la comunidad generan diferentes sentidos.

En las áreas rurales colombianas de Villapinzón y Mosquera que se tuvieron presentes para este estudio, los relatos de las personas son amplios puesto que se recogen experiencias tanto de adultos y adultos mayores con edades aproximadamente entre 40 y 70 años, los cuales narran sucesos relacionados con la disputa entre conservadores y liberales. También en los relatos se expresa eventos específicos relacionados con la presencia de grupos paramilitares y guerrilleros en regiones cercanas a los municipios hace varias décadas, experiencias que aún se cuentan y que se constituyen como un referente para comprender, por ejemplo, cuáles son los principales actores del conflicto armado interno colombiano. Aunque estas personas no participen directamente en el conflicto armado interno colombiano, los roles que cumplen en la sociedad generan un saber donde las nuevas generaciones aprendemos de sus historias y momentos que han vivido.

Los participantes identifican que la no implementación de la constitución política, la no consecución de los derechos humanos, la impunidad y la corrupción de actores políticos determinan dificultades en la construcción de paz en Colombia.
Para los participantes los contextos familiar y educativo son un referente para el desarrollo personal y social y, por ello, están involucrados en las dinámicas de conflicto, violencia y paz.

En los contextos rural y urbano, la violencia tiene manifestaciones particulares que, sin embargo, comparten la deslegitimación y la impunidad. La violencia sería entonces para los participantes un fenómeno constitutivo de la historia del país que ha logrado transformar las dinámicas relacionales de los colombianos y su cotidianidad.

En coherencia con lo anterior, los participantes identifican que la violencia y el conflicto emergen en los escenarios cotidianos (evolucionando y complejizándose hasta presentarse en esferas políticas de la sociedad), siendo estos mismos contextos esenciales para la construcción de paz. Respecto a los sentidos que los participantes expresan que les permiten diferenciar un conflicto de la violencia, se encuentra que el primero se configura como una situación que puede ser negativa o positiva y que no necesariamente implica el uso de actos violentos como "agresiones y golpes". La determinación de la solución de un conflicto dependerá, según los participantes, de valores como la tolerancia y el respeto.

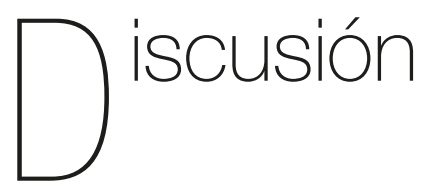

Curiosamente, aunque los participantes no se identifican como actores directos en el conflicto armado y la violencia (a 
excepción de los estudiantes universitarios), todos convergen en la comprensión de que son responsables, en conjunto con toda la sociedad colombiana, de la construcción de paz. Los actores identificados dentro de la violencia (FARC, ELN, BACRIM, paramilitares, Fuerzas Armadas y M19, entre otros) coinciden con los del conflicto armado, aunque se puntualiza nuevamente que la violencia se presenta constantemente en microsistemas desde la intencionalidad de actos violentos. Estos actos tienen manifestación por medio de agresión física y psicológica a un individuo o a un grupo, retomando a Martín-Baró (2003) se comprenden por medio de cuatro características; el fondo ideológico, comprendido como la razón fundamentada en una idea la cual es desencadenante del acto, la ecuación personal, donde se mezcla la percepción subjetiva y las motivaciones, el contexto posibilitador o favorecedor del acto en el cual se lleva a cabo y la estructura formal del acto, lo cual involucra la planeación y la ejecución del mismo.

Lo anterior posiblemente se vincule con la comprensión referente a que el conflicto armado es un fenómeno social, difícil de contextualizar en las realidades particulares de los participantes. La población civil es identificada como principal afectada del conflicto armado interno colombiano. No es recurrente la caracterización y diferenciación entre "víctimas" y "victimarios" por parte de los 37 participantes teniendo en cuenta que también forman parte de la población civil en contexto urbano-rural y no han sido afectados de forma directa por el conflicto armado.

Se identifica que más allá de motivaciones para la construcción de la paz, la reciente historia colombiana se ha definido por intereses para perpetuar la guerra. En ese sentido se identifica que la búsqueda de poder económico y político de particulares ha determinado el conflicto armado interno colombiano. La guerra es comprendida como un negocio en el que incluso los integrantes del Estado Colombiano han estado involucrados. Así, se establece una desarticulación entre las acciones políticas (comprendidas como lejanas) y las necesidades y realidades de los ciudadanos colombianos, situación que genera, por ejemplo, incredulidad frente al actual Proceso de Paz y conversaciones adelantadas entre el Estado y las FARC en la Habana, Cuba.

La diferenciación planteada por los participantes entre conflicto y violencia es coherente con los planteamientos de Parra (2008) en el sentido en que la segunda es tan solo una posibilidad de resolución de un conflicto. Si bien la autora plantea que dicha resolución dependerá de la comprensión que se tenga del conflicto, los participantes de la investigación asumen que el abordaje de los conflictos en las relaciones se determina por valores morales como la tolerancia y el respeto.

Los factores que han influido en la prolongación del conflicto interno colombiano identificados por el Grupo de Memoria Histórica (2013) son coherentes con aquellos mencionados por los participantes, ambos reconocen la presencia de un problema agrario, caracterizado por las dificultades que atraviesa el sector en relación con su proceso de crecimiento económico, como elementos propios de este problema los participantes distinguen "el nivel de competitividad en el mercado al que se enfrenta el campesino promedio en relación a las industrias multinacionales que también proveen al país, 
la calidad de los servicios públicos que presta el estado y las dificultades que esto trae en la vida y la calidad del trabajo de los campesinos". Entre los que también se mencionan "la falsa democracia" entendida en términos de una incongruencia entre las propuestas de los gobernantes y las acciones que llevan a cabo, el narcotráfico, la impunidad concedida a los delincuentes y la corrupción. Además, así como lo menciona el Grupo de Memoria histórica (2013) y Amnistía Internacional (2008), los participantes identifican la población civil como principal afectada por el conflicto armado colombiano, en la medida en la que esta se ve involucrada sin tomar parte en alguno de los bandos beligerantes (es decir, sin ser parte de las fuerzas militares estatales, ni del grupo al margen de la ley).

Si bien Barreto y Borja (2007) afirman que la violencia, desde una dimensión política, se constituye como el medio para dominar a otros, los participantes también reconocen que la violencia y el mismo conflicto armado colombiano tiene como su principal función la búsqueda del poder, particularmente económico y político, por ejemplo en la medida en la que diferentes grupos armados se apoderan de las tierras de los campesinos incurriendo en el abuso de los derechos de esta población y generando situaciones de desplazamiento forzado. Por otro lado, los participantes coinciden en reconocer que la violencia se da en diversidad de contextos y situaciones (ej. contexto familiar), de este modo coinciden con el Grupo de Memoria Histórica (2013) cuando se refiere a la multivariedad de la violencia (política, socioeconómica, física, sobre los territorios, socio-cultural), incluso cuando se presenta a lo largo de la historia, de acuerdo al carácter histórico comprendido por Martín-Baró (2003), en el que la violencia se filtra en los contextos microsociales y cotidianos de los colombianos a través de la manutención de un discurso que se caracteriza por situar al individuo en una sociedad hostil en la que hay que reaccionar, muchas veces, de manera violenta.

Aunque la mayoría de los participantes no se sientan directamente afectados por el conflicto armado, identifican que en todos los territorios y poblaciones tiene una repercusión, convergiendo con los planteamientos que hacen Mogollón, Vásquez y García, (2003), quienes reconocen afectaciones en la salud mental, la cultura cotidiana y las dinámicas relacionales de todos los colombianos, independientemente si estos son afectados directa o indirectamente por la violencia en el marco del conflicto.

Para los participantes el concepto de paz está relacionado en gran medida con lo que menciona Mesa (2008) respecto a la paz positiva, entendida esta como los elementos necesarios para construir una cultura de paz sostenible. Lo anterior se puede evidenciar en las afirmaciones de los participantes de que la paz debe ser construida desde las familias y otros contextos como las instituciones educativas, superando la dimensión política formal. Reconociendo la paz desde la cotidianidad, se parte de que para su real consolidación es necesaria la garantía del bienestar de todos los colombianos desde la consecución de los derechos humanos. Lo anterior se relaciona con la UNESCO (1999), cuando se hace referencia a que la cultura de paz es la acción que busca legitimar una convivencia sana donde se haga evidente la superación de la inequidad. 
Al hablar de inequidad se hace referencia directamente al valor de justicia, se diferencia a la desigualdad puesto que refiere a una problemática en una determinada población y es necesario conocer sus causas determinantes y formarse un juicio sobre la justicia o injusticia de dichas causas (Análisis de Situación en Salud [ASIS], 2010). En la presente investigación es evidente este fenómeno al visibilizar la voz de actores directos o indirectos, quienes se han visto envueltos en problemáticas de orden social mediados por la violencia y el conflicto armado, las cuales han generado condiciones de injusticia impidiendo la superación dificultades y la legitimación de la paz.

En coherencia con la comprensión cotidiana de la paz, todos los participantes convergen en la idea de que es de "todos" la responsabilidad de su construcción, identificando la oportunidad que esto brinda como escenario para reconstruir el tejido social de un país que se encuentra fragmentado. Posiblemente los recientes cambios históricos que Colombia ha vivido y vive hayan generado modificaciones en la forma en que los ciudadanos se posicionan frente a su realidad sociopolítica, ya que los resultados de la presente investigación contrastan con lo afirmado por Sacipa (2005) en su estudio con ciudadanos de Bogotá, donde identifica que para ellos los Bogotanos la paz es un fenómeno lejano que está en manos de otros y no como responsabilidad propia (lo que se asocia a la comprensión negativa de la paz).

Finalmente, los hallazgos de la presente investigación resaltan que los significados y sentidos que la población civil le atribuye a la construcción de paz desde la cotidianidad son una gran herramienta posibilitadora de cambio social, en tanto le permite a los participantes reconocerse como actores activos y responsables de acciones de transformación cultural desde sus contextos locales.

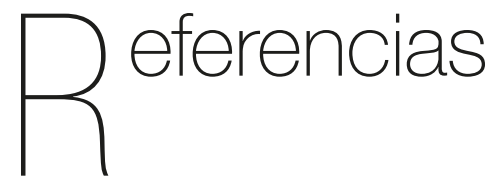

Aigneren, M. (2009). La técnica de recolección de información mediante los grupo focales. Recuperado de: https://aprendeenlinea.udea.edu.co/ revistas/index.php/ceo/article/.../1264

Abela, J. (2003). Las técnicas de Análisis de Contenido: una revisión actualizada. Recuperado del 09 de abril de 2015, de http://public.centrodeestudiosandaluces. es/pdfs/S200103.pdf

Alzate, M. (2010). Interpretaciones y aportes recientes sobre las acciones colectivas frente a la violencia y el conflicto armado en Colombia. Revista de Investigación Científica, 18(36), 1-24 Recuperado de http://dialnet.unirioja.es/servlet/ articulo?codigo $=3266649$

Amnistía Internacional (2008). ¡Déjennos en paz! La población civil, víctima del conflicto armado colombiano. Bogota: Amnistía Internacional.

Análisis de Situación en Salud (2010) Análisis de la situación de salud en Colombia 20022007. Ministerio de la protección social. República de Colombia. 
Arcila, P., Mendoza, L., Jaramillo, J., \& Cañón, O. (2010). Comprensión del significado desde Vygotsky, Bruner y Gergen. Diversitas: Perspectivas en Psicología, 6(1), 37-49

Arévalo, W. (14 de junio de 2014). Un conflicto de definiciones. El Espectador. Recuperado de: http://www.elespectador.com/noticias/ politica/un-conflicto-de-definicionesarticulo-498374

Martín-BaróBaro, I. (2003). Poder, Ideología y Violencia. Madrid. Editorial Trotta.

Barreto, I., \& Borja, H. (2007). Violencia política: algunas consideraciones desde la psicología social. Revista Diversitas: Perspectivas en Psicología, 3 (1), 109-139.

Blair, E. (2009). Aproximación Teórica al concepto de violencia: Avatares de una definición. Política y Cultura, 9 (32), 9-33.

Botero, P., Pinilla, V., Lugo, N. \& Calle, A. (2012). Narrativas del conflicto en contextos locales de Colombia. Revista Latinoamericana de Ciencias Sociales, Niñez y Juventud, 10 (1), 715-720.

Calle, A. (2011). Sentido Político de las narraciones de jóvenes de Colombia en conflicto. Revista Latinoamericana de Ciencias Sociales, Niñez y Juventud, 9(2), 63-96.

CAVIDA (2002). Somos tierra de esta tierra: Memorias de una resistencia civil. Cacarica, Chocó y Colombia. República de Colombia.

Cisneros, C. A. (2007). Los rostros deconstructivo y reconstructivo de la construcción social. Kenneth Gergen en conversación con César A. CisnerosPuebla. Introducción de Robert B.
Faux [83 párrafos]. Forum Qualitative Sozialforschung / Forum: Qualitative Social Research, 9(1).

Comité Internacional de la Cruz Roja (2008). ¿Cuál es la definición de "conflicto armado" según el derecho internacional humanitario? (p.1-6). Recuperado de https://www.icrc.org/spa/assets/files/ other/opinion-paper-armed-conflict-es.pdf

Comisión Intereclesial de Justicia y Paz. (20 de agosto de 2013). Nuestras razones de ser. República de Colombia. Recuperado de http://justiciaypazcolombia.com/ Nuestra-Identidad

Colectivo loé. (2010) ¿Para qué sirve el grupo de discusión?. EMPIRIA. Revista de Metodología de Ciencias Sociales, 19, 73-99.

Grupo de Memoria Histórica. (2013). ¡BASTA YA! Colombia: Memorias de Guerra y Dignidad. Bogotá: Imprenta Nacional.

Ibañez, T. (2003). La Construcción Social del Socioconstruccionismo: retrospectiva y perspectivas. Política y Sociedad, (40)1, 155-160.

Lanzadabal , D., Paez., D., \& Pineda, E. (2013). Diseño de una innovación pedagógica para la formación en investigación apoyada en ambientes digitales. Revista Virtual Universidad Católica del Norte, 40(13), 4-30.

Martín-Crespo, C., \& Salamanca, A. (2007). El Muestreo en la Investigación Cualitativa. Nure Investigación, 27, 211-221

Martínez, M. (2006). La Investigación Cualitativa (Síntesis Contextual). Revista de Investigación en Psicología, 1(9), 123-146. 
Mesa, M. (2008). Sociedad civil y construcción de la paz: una agenda inconclusa. Artículo Publicado en Pensamiento Propio $n^{a} 28$. CEIPAZ-Fundación Cultura de Paz.

Mogollón, A., Vásquez, M., \& García, M. (2003). Necesidades en salud de la población desplazada por conflicto armado en Bogotá. Revista Española de Salud Pública. (77), 2. Recuperado de: http://scielo.isciii.es/scielo.php?pid=S1135$57272003000200008 \&$ script $=$ sci_ arttext\&tlng=e

Osorio, F. (2005). Jóvenes rurales y acción colectiva en Colombia. Nómadas, 23, 122-130.

Parra, L. (2008). Introducción a la Psicología de la Guerra. El ágora USB. 8(2), 269-280.

Organización de las Naciones Unidas para la Educación, la Ciencia y la Cultura. (UNESCO). (1999). Movimiento mundial para la cultura de paz y no violencia. p. 12. Quito: Autor. Recuperada de http://www. unesco.org/cpp/sp/proyectos/cppinfo.htm
Unidad para la Atención y Reparación Integral a las Víctimas. (2015). Red Nacional de Información. Información al Servicio de las Víctimas. Recuperado de http://rni. unidadvictimas.gov.co/v-reportes

Rettberg, A. (2002). Preparar el futuro: Conflicto y postconflicto en Colombia. Bogotá: Universidad de los Andes y Fundación Ideas para la Paz.

Sacipa, S. (2005). Las y los ciudadanos de Bogotá significan la paz. Universitas Psychologica, 4, 97-106.

Sacipa, S., Tovar, C., Sarmiento, L., Gómez, A., \& Suarez, M. (2013). La psicología política en Colombia. (23). Universidad de Manizalez, Recuperado de: http://lodel. irevues.inist.fr/cahierspsychologiepolitique/ index.php?id=2552559 